\title{
Medical disorders in Alzheimer's disease and vascular dementia
}

\author{
Hans Förstl ${ }^{1}$, Nigel Cairns ${ }^{2}$, Alistair Burns ${ }^{3}$ and Philip Luthert ${ }^{2}$ \\ Departments of ${ }^{1}$ Old Age Psychiatry and ${ }^{2}$ Neuropathology, MRC Alzheimer Disease Brain Bank, \\ Institute of Psychiatry, de Crespigny Park, London SE5 8AF, UK
}

\begin{abstract}
Summary: The clinical and postmortem findings of 29 patients with Alzheimer's disease were evaluated and compared to the findings of 19 patients with vascular dementia. The patients with Alzheimer's disease had received treatment for an average of $\mathbf{2 . 0}$ internal medical disorders, the patients with vascular dementia for 2.1 disorders. The average number of medical diseases found at postmortem was 3.7 in the group with Alzheimer's dementia and 4.1 in vascular dementia. Apart from a marginally increased rate of peripheral occlusive artery disease in vascular dementia, the proportions of the most common disorders of the cardiovascular, genitourinary, gastrointestinal and endocrinological disorders and the most common causes of death did not differ significantly between these groups. Therefore patients with Alzheimer's disease should receive the same internal medical attention as patients with vascular dementia.
\end{abstract}

\section{Introduction}

A recent study has suggested that patients with dementia of the Alzheimer-type are 'healthier' than other elderly outpatients in terms of the number of diagnosed medical disorders and amount of prescribed medication. ${ }^{1}$ In several studies which have compared patients with clinically diagnosed Alzheimer type dementia and vascular dementia, the Alzheimer patients had significantly less cardiovascular and metabolic disturbances. ${ }^{2-4}$ Case-control studies, on Alzheimer patients only, have found spurious increases of respiratory tract infection, pyrexia, cystitis or pyelonephritis, but no definite conclusions could be drawn from these inconsistent results. ${ }^{5,6}$

In view of these findings it would be expected that patients with neuropathologically proven Alzheimer's disease show a lower proportion of general medical disorders when compared to patients with vascular dementia. No previously published attempt has been made to test this hypothesis, which deserves interest in view of the large number of elderly demented patients who need medical attention.

Correspondence: H. Förstl, M.D.

Accepted: 20 February 1991

\section{Methods}

Forty-eight consecutive demented patients who fulfilled the criteria for the neuropathological diagnosis of either vascular dementia or Alzheimer's dementia, which have been described previously, ${ }^{6}$ were included in this stucy. Eight patients with mixed forms of vascular and Alzheimer's dementia and 7 patients with other dementing disorders (progressive supranuclear palsy, Lewy-body dementia) were excluded. The samples were otherwise unselected. Their demographic characteristics are shown in Table I. A full hospital postmortem examination was performed in each case. These assessments were performed and reported 'blind' to the nature of the patients' dementia. Brains were

Table I Demographic characteristics of patients with neuropathologically proven Alzheimer's disease and vascular dementia

\begin{tabular}{lcc}
\hline & $\begin{array}{c}\text { Alzheimer's } \\
\text { disease }\end{array}$ & $\begin{array}{c}\text { Vascular } \\
\text { dementia }\end{array}$ \\
\hline Patient number & 29 & 19 \\
Male/female ratio & $8 / 21$ & $5 / 14$ \\
Age range in years (mean) & $66-94(80)$ & $66-90(81)$ \\
Duration of illness in years & $1-13(8)$ & $1-14(5)$ \\
$\quad$ (mean) & & \\
\hline
\end{tabular}


extensively examined according to current practice in the MRC Alzheimer Disease Brain Bank at the Institute of Psychiatry. ${ }^{7}$ The significance of differences between the total (mean) numbers of diagnoses and the number of individual diagnoses was tested using $t$-tests or chi-square-tests (Yates correction was applied where necessary); severity ratings of the postmortem findings were compared using the Kruskal-Wallis test. ${ }^{8}$

\section{Results}

Alzheimer patients had received treatment for an average of 2.0 medical diseases. (s.d. 1.1), patients with vascular dementia for 2.1 disease (s.d. 1.1). Neither the frequency of individual clinically observed disorders, e.g. diabetes mellitus, nor of groups of diseases, e.g. endocrinological disease, showed significant differences between Alzheimer or vascular dementia.

At postmortem, chronic diseases of the cardiovascular, of the genitourinary and of the gastrointestinal system were most frequently found (Table II). The proportion of patients with occlusive peripheral arterial disease was only marginally lower in Alzheimer's than in vascular dementia $(P<0.1)$. There was no difference in the proportion of subjects with coronary artery disease between the groups. Differences in the severity of occlusive peripheral artery disease (4 severe cases in Alzheimer versus 5 in vascular dementia) and coronary artery diseases (4 versus 4 ) did not reach

Table II Most frequent postmortem findings

\begin{tabular}{lccc}
\hline & $\begin{array}{c}\text { Alzheimer's } \\
\text { disease } \\
n=29\end{array}$ & $\begin{array}{c}\text { Vascular } \\
\text { dementia } \\
n=19\end{array}$ & \\
\hline $\begin{array}{c}\text { Cardiovascular system } \\
\text { coronary artery } \\
\text { disease }\end{array}$ & 14 & 9 & n.s. \\
$\begin{array}{c}\text { occlusive peripheral } \\
\text { artery disease }\end{array}$ & 11 & 13 & $(<0.1)$ \\
$\begin{array}{c}\text { myocardial infarction } \\
\text { myocardial dilatation } \\
\text { myocardial } \\
\text { hypertrophy }\end{array}$ & 7 & 4 & n.s. \\
$\begin{array}{c}\text { Genitourinary system } \\
\text { kidney disease }\end{array}$ & 3 & 4 & n.s. \\
$\begin{array}{c}\text { Gastrointestinal tract } \\
\text { cholelithiasis } \\
\text { liver disease }\end{array}$ & 9 & 4 & n.s. \\
$\begin{array}{c}\text { Endocrinological glands } \\
\text { thyroid disease }\end{array}$ & 4 & 3 & n.s. \\
\hline
\end{tabular}

n.s. = not significant. statistical significance. An average of 3.7 (s.d. 1.1) pathological medical conditions was diagnosed in the postmortems of the Alzheimer patients and of 4.1 (s.d. 1.5) in those with vascular dementia.

Pneumonia represented by far the commonest acute and fatal medical disorder in both types of dementia followed by myocardial infarction (Table III).

\section{Discussion}

The number of clinically and pathologically diagnosed chronic medical diseases was similar in neuropathologically proven Alzheimer's disease and in vascular dementia. The finding of a higher proportion of occlusive peripheral arterial disease in vascular dementia is in keeping with earlier results. ${ }^{2-4}$ Several investigations have shown that cardiovascular disorders do also occur in a significant number of Alzheimer patients. ${ }^{3,4}$ However, other clinical investigations suggested that $\mathrm{Alz}$ heimer's disease, in contrast to vascular dementia, would be characterized by the absence of cardiovascular disorders. ${ }^{2}$ The discrepancy between our results and former clinical or epidemiological studies, which relied on strict clinical criteria for the intravital diagnosis of probable dementia of the Alzheimer type, ${ }^{9}$ could partly be explained by a selection artefact: in clinical studies, demented patients, who show additional evidence of cardiovascular disorders or other conditions which might cause cognitive impairment, can not be classified as suffering from 'probable' Alzheimer's disease. In practice $^{8}$ this approach may lead to an underestimation of relevant general medical disorders in patients who received a specialist diagnosis of probable Alzheimer's disease.

Greater agreement exists concerning the leading acute causes of death in dementia. Pneumonia has repeatedly been proven to be the commonest acute terminal illness. ${ }^{10,11}$ In these samples it was followed by myocardial infarction irrespective of the underlying diagnosis.

Table III Cause of death

\begin{tabular}{lccc}
\hline Causes of death & $\begin{array}{c}\text { Alzheimer's } \\
\text { disease }\end{array}$ & $\begin{array}{c}\text { Vascular } \\
\text { dementia }\end{array}$ & \\
\hline Pneumonia & 17 & 9 & n.s. \\
$\begin{array}{l}\text { Acute myocardial } \\
\text { infarction }\end{array}$ & 4 & 3 & n.s. \\
$\begin{array}{l}\text { Other conditions } \\
\text { Unknown }\end{array}$ & 3 & 3 & n.s. \\
\hline
\end{tabular}

n.s. = not significant 
In conclusion, this study suggests that the proportion of patients with histologically proven Alzheimer dementia who have concomitant medical disorders is similar to that in vascular dementia. The belief that Alzheimer patients are 'healthier' may be explained by a sample bias related to strict criteria for the clinical diagnosis. ${ }^{6}$

\section{References}

1. Wolf-Klein, G.P., Silverstone, F.A., Brod, M.S. et al. Are Alzheimer patients healthier? J Am Geriatr Soc 1988, 36: 219-224.

2. Erkinjuntti, T. Differential diagnosis between Alzheimer's disease and vascular dementia: evaluation of common clinical methods. Acta Neurol Scand 1987, 76: 433-442.

3. Thal, L.J., Grundman, M. \& Klauber, M.R. Dementia: characteristics of referral population and factors associated with progression. Neurology 1988, 38: 1083-1090.

4. Tresch, D.D., Folstein, M.F., Rabins, P.V. et al. Prevalence and significance of cardiovascular disease and hypertension in elderly patients with dementia and depression. $\mathrm{J} \mathrm{Am}$ Geriatr Soc 1985, 33: 530-537.

5. Henderson, A.S. The risk factors for Alzheimer's disease: a review and a hypothesis. Acta Psychiatr Scand 1988, 78: 257-275.

6. Förste, H. Internistiche vor-Begleit-und Folgeer krankungen der Demenz vom Alzheimer-Typ. Med Klinik 1990, 85: 725-728.

\section{Acknowledgements}

The MRC Alzheimer Disease Brain Bank is supported by the Medical Research Council (UK). The preparation of the manuscript was supported by a grant of the Deutsche Forschungsgemeinschaft (DFG) to H.F.

7. Burns, A., Luthert, P., Levy, R., Jacoby, R. \& Lantos, P. Accuracy of clinical diagnosis of Alzheimer's disease. $\mathrm{Br}$ Med $J$ 1990, 301: 1026.

8. Norusis, M.J., SPSS-PC + V2. Chicago: SPSS, 1988.

9. McKhann, G., Drachman, D., Folstein, M. et al. Clinical diagnosis of Alzheimer's disease: report of the NINCDSADRDA work group under the auspices of Department of Health and Human Services Task Force on Alzheimer's disease. Neurology 1984, 34: 939-944.

10. Sulkava, R., Haltia, M., Paetau, A. et al. Accuracy of clinical diagnosis in primary degenerative dementia: correlation with neuropathological findings. J Neurol Neurosurg Psychiatry 1983, 46: 9-13.

11. Mölsä, P.K., Marttila, R.J. \& Rinne, U.K. Survival and cause of death in Alzheimer's disease and multi-infarct dementia. Acta Neurol Scand 1986, 74: 103-107. 